\section{IN VITRO EFFECT OF N-ACETYL-L-CYSTEINE ON GLUTATHIONE AND SULFHYDRYL LEVELS IN X-LINKED ADRENOLEUKODYSTROPHY PATIENTS}

\author{
Desirèe Padilha Marchetti ${ }^{1}$, Bruna Donida ${ }^{1}$, Marion Deon ${ }^{2,3}$, \\ Carlos Eduardo Jacques ${ }^{1}$, Laura Bannach Jardim³ \\ Carmen Regla Vargas ${ }^{1,2,3}$
}

\begin{abstract}
Introduction: Recent evidence shows that oxidative stress seems to be related with the pathophysiology of X-linked adrenoleukodystrophy (X-ALD), a neurodegenerative disorder.
\end{abstract}

Methods: In the present study, the in vitro effect of N-acetyl-L-cysteine (NAC) on glutathione (GSH) and sulfhydryl levels in X-ALD patients was evaluated.

Results: A significant reduction of GSH and sulfhydryl content was observed in X-ALD patients compared to the control group. Furthermore, $5 \mathrm{mM}$ of NAC, in vitro, led to an increase in GSH content and sulfhydryl groups in these patients.

Conclusion: These data probably indicate that an adjuvant therapy with the antioxidant NAC could improve the oxidative imbalance in X-ALD patients.

Keywords: X-linked adrenoleukodystrophy; N-acetyl-L-cysteine; glutathione; sulfhydryl

X-linked adrenoleukodystrophy (X-ALD) is a peroxisomal disorder that affects at least 1 in 17,000 males ${ }^{1}$. Phenotypic variability is remarkable, ranging from severe and rapidly progressive forms (i.e., childhood cerebral form, CCER) to slowly progressive paraparesis compatible with life ${ }^{1}$.

Hexacosanoic acid (C26:0) and tetracosanoic acid (C24:0) are saturated fatty acids that accumulate in tissues and body fluids ${ }^{1}$. The exact mechanisms underlying brain damage in X-ALD are poorly elucidated. Some researchers have proposed that oxidative stress represents a hallmark in the pathogenesis of X-ALD ${ }^{2-4}$.

Glutathione (GSH) deficiency is associated with several pathological conditions, since the glutathione system provides the main cellular protection against oxidative damage. Cellular redox balance is assured by equilibrated ratios among glutathione forms; therefore, a decrease in GSH or an increase in its oxidized form (GSSG) reflects an oxidative perturbation in cell metabolism ${ }^{5}$.

The antioxidant capacity of NAC has been proposed based on data from in vitro studies, in which this compound has been shown to reduce oxidant-induced cell damage, acting as a cysteine prodrug and a GSH precursor $^{6}$. NAC can also reduce disulphide bonds in proteins, scavenge free radicals and bind metals to form complexes ${ }^{7}$. There are several in vitro and in vivo studies involving NAC action on X-ALD treatment ${ }^{8-11}$. Considering that NAC has been proposed as a GSH precursor, the purpose of this study was to analyze the in vitro effect of NAC on GSH and sulfhydryl levels in X-ALD patients.

\section{METHODS}

\section{Subjects}

A total of eight X-ALD patients [four heterozygotes (HTZ), one Addison-only and three CCER] were included in this study. These patients had their diagnosis confirmed by determination and mutation analysis of very long chain fatty
Clin Biomed Res. 2017;37(1):33-37

1 Programa de Pós-graduação em Ciências Biológicas, Universidade Federal do Rio Grande do Sul (UFRGS). Porto Alegre, RS, Brazil.

2 Programa de Pós-graduação em Ciências Farmacêuticas, Universidade Federal do Rio Grande do Sul (UFRGS). Porto Alegre, RS, Brazil.

3 Serviço de Genética Médica, Hospital de Clínicas de Porto Alegre. Porto Alegre, RS, Brazil.

Corresponding author: Desirèe Padilha Marchetti desireepmarchetti@gmail.com Serviço de Genética Médica, Hospital de Clínicas de Porto Alegre Rua Ramiro Barcelos, 2350. 90035-903, Porto Alegre, RS, Brazil. 
acids. The control group consisted of eight healthy subjects. This study was approved by the Ethics Committee of Hospital de Clínicas de Porto Alegre, RS, Brazil (protocol number 13-0247), and all subjects or parents gave written informed consent.

\section{Mutation Analysis}

Using 10 polymerase chain reactions (PCRs), it was possible to screen the entire coding sequence of the ABCD1 gene and intron-exon boundaries. All samples were screened by single strand conformational polymorphism analysis followed by automated DNA sequencing to establish the specific mutation. Amplicons with mobility shift were purified with Exo-SAP (GE Healthcare) and submitted to automated sequencing on $A B I 3100$ Genetic Analyzer using BigDye, version 3.0 (Life Technologies). Mutations were confirmed by reverse strand PCR sequencing.

\section{Sample Collection and in Vitro Assay}

Venous blood was collected under sterile conditions in heparinized vials. Immediately, aliquots of whole blood cells were incubated with NAC (2.5 and $5 \mathrm{mM})$ for 6 hours at $37^{\circ} \mathrm{C}^{8,12}$. Then, the blood was centrifuged at $1000 \times \mathrm{g}$ for 10 minutes and plasma was removed by aspiration, aliquoted and frozen at $-80{ }^{\circ} \mathrm{C}$ until sulfhydryl determination. Erythrocytes were washed three times with cold saline solution, lysated with water and frozen at $-80{ }^{\circ} \mathrm{C}$ until GSH analysis. NAC was diluted with phosphate-buffered saline (PBS buffer) on the day of use. The proportion of blood and antioxidant solutions diluted in PBS buffer was 1:3.

\section{Reduced GSH Content in Erythrocytes}

To measure GSH levels, lysates of erythrocytes were processed as described by Browne and Armstrong ${ }^{13}$. Results were expressed as $\mathrm{nmol} / \mathrm{mg}$ protein.

\section{Total Plasmatic Level of Sulfhydryl Groups}

The plasmatic concentration of sulfhydryl groups was determined as described by Aksenov and Markesbery ${ }^{14}$. The sulfhydryl content is inversely correlated to oxidative damage to proteins. Results were reported as $\mu \mathrm{mol} \mathrm{TNB} / \mathrm{mg}$ protein.

\section{Protein Determination}

Plasma and erythrocyte protein concentrations were determined, respectively, by Biuret method - using the commercial kit of Labtest ${ }^{\circledR}$ (Labtest Diagnóstica, Lagoa Santa, MG, Brazil) - and by the method of Lowry et al. ${ }^{15}$.

\section{Statistical Analysis}

Data were expressed as mean \pm standard error of the mean (SEM). Comparisons between means were analyzed by one-way analysis of variance (ANOVA) followed by Duncan's post hoc test. Differences were considered statistically significant when $P$ value was lower than 0.05 . Statistical analyses were performed using the Statistical Package for the Social Sciences (SPSS Inc., Chicago, IL, USA - SPSS, version 19.0) software, and graphics were produced using the GraphPad Prism (GraphPad Software Inc., San Diego, CA, USA — version 5.0) software.

\section{RESULTS}

\section{Patient and Control Information}

Table 1 shows patient and control information (average and standard deviation of age, gender and phenotype).

\section{In vitro effect of NAC on GSH content}

Figure 1 shows GSH erythrocytes levels and the in vitro effect of NAC (2.5 and $5 \mathrm{mM})$ on GSH content in X-ALD patients (HTZ, CCER and Addisononly). These three phenotypes were included in the same group because there was no significant difference in GSH levels between them [mean and SEM of female HTZ: $0.87 \pm 0.82$; mean and SEM of male patients (including the Addison-only patient): $0.66 \pm 0.90, P=0.68$, Duncan's post hoc test]. GSH concentration significantly decreased in these patients and $5 \mathrm{mM}$ of NAC increased these levels, reaching control values $[\mathrm{F}(3,19)=10.41$, $P<0.001]$.

Table 1: Patients and controls' information.

\begin{tabular}{lcc}
\hline Subjects & Ages (years-old) & $\begin{array}{c}\text { Phenotypes/ } \\
\text { genders }\end{array}$ \\
\hline Patient 1 & 29 & Heterozygote woman \\
Patient 2 & 38 & Heterozygote woman \\
Patient 3 & 49 & Heterozygote woman \\
Patient 4 & 50 & Heterozygote woman \\
Patient 5 & 9 & Cerebral form male \\
Patient 6 & 9 & Cerebral form male \\
Patient 7 & 14 & Cerebral form male \\
Patient 8 & 14 & Addison-only male \\
Mean \pm SD & $27.12 \pm 16.77$ & - \\
Control 1 & 23 & Male \\
Control 2 & 23 & Male \\
Control 3 & 23 & Male \\
Control 4 & 24 & Male \\
Control 5 & 26 & Woman \\
Control 6 & 26 & Woman \\
Control 7 & 27 & Woman \\
Control 8 & 30 & Woman \\
Mean \pm SD & $25.25 \pm 2.49$ & - \\
\hline
\end{tabular}




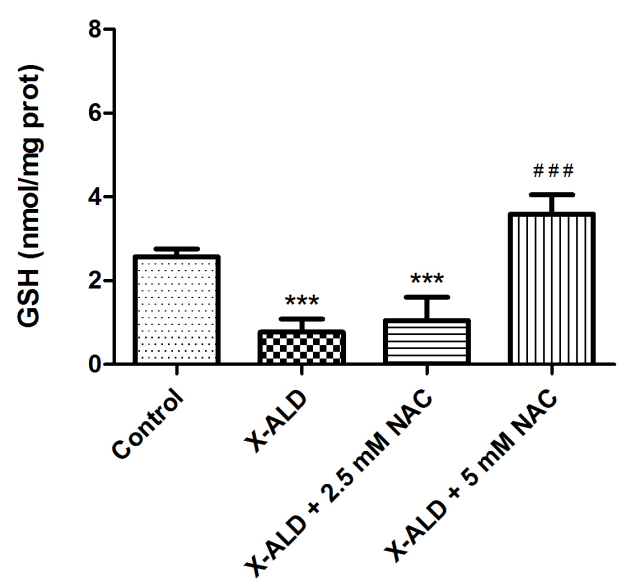

Figure 1: The in vitro effect of N-acetyl-L-cysteine (NAC) (2.5 and $5 \mathrm{mM}$ ) on GSH levels in erythrocytes from X-ALD patients. Data represent mean \pm standard error of the mean. ${ }^{* * *} P<0.001$ compared to the control group and ${ }^{\# \#} P<0.001$ compared to X-ALD patients with NAC $2.5 \mathrm{mM}$ and X-ALD patients [one-way analysis of variance (ANOVA) followed by Duncan's multiple range test].

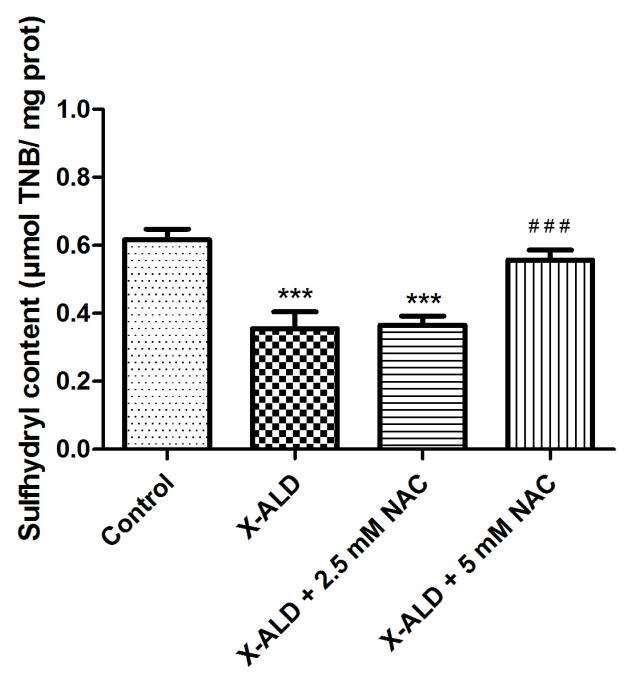

Figure 2: The in vitro effect of $\mathrm{N}$-acetyl-L-cysteine (NAC) ( 2.5 and $5 \mathrm{mM}$ ) on sulfhydryl content in plasma from $X$-ALD patients. Data represent mean \pm standard error of the mean. ${ }^{* * *} P<0.001$ compared to the control group and ${ }^{\# \#} P<0.001$ compared to X-ALD patients with NAC $2.5 \mathrm{mM}$ and X-ALD patients [one-way analysis of variance (ANOVA) followed by Duncan's multiple range test].

\section{In vitro effect of NAC on Sulfhydryl content}

Figure 2 shows sulfhydryl plasma levels and the in vitro effect of NAC ( 2.5 and $5 \mathrm{mM}$ ) on sulfhydryl content in X-ALD patients (HTZ, CCER and Addison-only). These three phenotypes were included in the same group because there was no significant difference in sulfhydryl content between them [mean and SEM of female HTZ: $0.29 \pm 0.11$; mean and SEM of male patients (including the Addison-only patient): $0.38 \pm 0.10, P=$ 0.25 , Duncan's post hoc test]. Sulfhydryl content was significantly reduced in these patients and $5 \mathrm{mM}$ of NAC increased these levels until they reached control values $[\mathrm{F}(3.20)=16.47, P<0.001]$.

\section{DISCUSSION}

Several studies have shown that oxidative stress is induced in X-ALD patients, including oxidative damage to protein, lipids, and reduction of antioxidant capacity $4,5,16$. Previous research has demonstrated a reduction in GSH and sulfhydryl content in X-ALD patients ${ }^{5,17}$. Interestingly, low levels of GSH have also been reported in an animal model for X-ALD ${ }^{9}$. The present study showed that X-ALD patients had lower GSH and sulphydryl levels compared to the control group, which is consistent with the literature. Besides, $5 \mathrm{mM}$ of NAC, in vitro, increased GSH content and sulfhydryl groups in these patients.

GSH plays a wide variety of physiological roles and its antioxidant effects depend on the presence of the free sulfhydryl group as a ready source of reducing equivalents to quench radical species. GSH also acts as a "scavenger" of free radicals ${ }^{18}$. The limiting step of the GSH synthesis involves conjugation of cysteine with L-glutamate, while L-glycine is added in a subsequent synthetic step by GSH synthase. GSH depletion is a feature of a wide range of neuropsychiatric disorders, including Alzheimer and Parkinson diseases, and in some inborn errors of metabolism ${ }^{5,19}$.

Adjuvant therapies with antioxidant have been studied in disease-associated oxidative stress. NAC is a cysteine prodrug with an antioxidant activity attributed to its sulfhydryl group, which provides protection against oxidative and metabolic processes. NAC supplies the cysteine necessary for GSH synthesis and has proven to be effective in treating disease-associated oxidative stress ${ }^{7}$.

It has been shown that NAC crosses the blood-brain barrier, accumulated in the brain, and reverses memory impairment and brain oxidative stress in aged mice ${ }^{20}$. Additionally, in some murine models of Alzheimer disease, the administration of NAC buffered oxidative damage ${ }^{21}$. In an animal model of Duchenne muscular dystrophy, the treatment with NAC significantly decreased the oxidation of GSH and protein thiols, and enhanced muscle protein thiol content ${ }^{22}$.

In a clinical trial with Gaucher and Parkinson patients, NAC increased whole blood GSH/GSSG ratio and GSH concentration in the brain ${ }^{23}$. Rushworth et al. ${ }^{24}$ suggested that NAC might be useful not only for promoting GSH depletion, but also because NAC-derived cysteine can potentially lead to an increase in the release of glutamate from astrocytes resulting in activation of neuronal glutamate receptors. 
Regarding studies involving the effect of NAC on X-ALD, Tolar et al. ${ }^{11}$ reported that peri-transplant administration of NAC was protective from fulminant demyelination in advanced symptomatic X-ALD patients. It was also seen that a pre-treatment with arginine and NAC inhibited nitrite and superoxide production in glial cells enriched with $\mathrm{C} 26: 0^{8}$. Additionally, NAC in combination with other antioxidants reversed oxidative damage and energetic failure in an animal model for X-ALD ${ }^{10}$.

As to the underlying mechanisms by which NAC increases sulfhydryl and GSH levels, it is possible to assume that this action is probably due to stimulation of enzymes related to the GSH synthesis or to non-enzymatic mechanisms related to scavenger properties of free radicals.

Finally, the present results confirm former reports showing the role of oxidative stress on X-ALD and demonstrate, for the first time in the literature, the in vitro protective effect of NAC on GSH and sulfhydryl content in this disease. Therefore, this study underscores the pertinence of using antioxidants as an adjuvant therapy for X-ALD to improve oxidative imbalance in $X$-ALD patients. However, the present in vitro study should be interpreted with caution and more in vivo experiments are necessary to elucidate this issue.

\section{INFORMED CONSENT}

All procedures followed in this study were in accordance with the ethical standards of the responsible (institutional and national) committee on human experimentation and with the Helsinki Declaration of 1975 , as revised in 2000 . Informed consent was obtained from all patients for inclusion in the study.

\section{ABBREVIATIONS}

C24:0: Tetracosanoic acid; C26:0: Hexacosanoic acid; CCER: Childhood cerebral form; GSH: Glutathione; GSSG: Oxidized glutathione; NAC: N-acetyl-L-cysteine; PBS: Phosphate-buffered saline; X-ALD: X-linked adrenoleukodystrophy.

\section{Acknowledgements}

This study was supported by Brazilian agencies Coordenação de Aperfeiçoamento de Pessoal de Nível Superior (CAPES), Conselho Nacional de Desenvolvimento Científico e Tecnológico (CNPq) and Fundo de Incentivo à Pesquisa e Eventos (FIPE/HCPA). The authors also thank the patients, their families and the staff from Serviço de Genética Médica/Hospital de Clínicas de Porto Alegre. Carmen R. Vargas and Laura B. Jardim are supported by CNPq.

\section{REFERENCES}

1. Moser HW, Smith KD, Watkins PA, Powers J, Moser AB. X-linked adrenoleukodystrophy. In: Scriver CR, Beaudet AL, Sly WS, Valle D, editors. The metabolic and molecular bases of inherited disease. 8th ed. New York: McGraw-Hill Inc; 2001. p. 3257-301.

2. Berger J, Forss-Petter S, Eichler FS. Pathophysiology of X-linked adrenoleukodystrophy. Biochimie. 2014;98:135-42. PMid:24316281. http://dx.doi.org/10.1016/j. biochi.2013.11.023.

3. Galea E, Launay N, Portero-Otin M, Ruiz M, Pamplona R, Aubourg P, Ferrer I, Pujol A. Oxidative stress underlying axonal degeneration in adrenoleukodystrophy: a paradigm for multifactorial neurodegenerative diseases? Biochim Biophys Acta. 2012;1822:1475-88.

4. Vargas CR, Wajner M, Sirtori LR, Goulart L, Chiochetta M, Coelho $D$, et al. Evidence that oxidative stress is increased in patients with $X$-linked adrenoleukodystrophy. Biochim Biophys Acta. 2004;1688:26-32.
5. Petrillo S, Piemonte F, Pastore A, Tozzi G, Aiello C, Pujol A, et al. Glutathione imbalance in patients with X-linked adrenoleukodystrophy. Mol Genet Metab. 2013;109(4):36670. PMid:23768953. http://dx.doi. org/10.1016/j.ymgme.2013.05.009.

6. Zafarullah M, Li WQ, Sylvester J, Ahmad M. Molecular mechanisms of $\mathrm{N}$-acetylcysteine actions. Cell Mol Life Sci. 2003;60(1):6-20. PMid:12613655. http://dx.doi.org/10.1007/ s000180300001.

7. Atkuri KR, Mantovani JJ, Herzenberg LA, Herzenberg LA. N-Acetylcysteine: a safe antidote for cysteine/glutathione deficiency. Curr Opin Pharmacol. 2007;7(4):355-9. PMid:17602868. http://dx.doi.org/10.1016/j. coph.2007.04.005.

8. Di Biase A, Di Benedetto R, Salvati $S$, Attorri L, Leonardi F, Pietraforte D. Effects of L-mono methyarginine, $\mathrm{N}$-acetyl-cysteine and diphenyleniodonium on free radical release in $\mathrm{C} 6$ glial cells enriched in hexacosenoic acid. Neurochem Res.
2005;30(2):215-23. PMid:15895825. http://dx.doi.org/10.1007/s11064-0042444-8.

9. Galino J, Ruiz M, Fourcade S, Schlüter A, López-Erauskin J, Guilera C, et al. Oxidative damage compromises energy metabolism in the axonal degeneration mouse model of X-adrenoleukodystrophy. Antioxid Redox Signal. 2011;15(8):2095107. PMid:21453200. http://dx.doi. org/10.1089/ars.2010.3877.

10. López-Erauskin J, Fourcade S, Galino J, Ruiz M, Schlüter A, Naudi $A$, et al. Antioxidants halt axonal degeneration in a mouse model of X-adrenoleukodystrophy. Ann Neurol. 2011;70(1):84-92. PMid:21786300. http://dx.doi.org/10.1002/ana.22363.

11. Tolar J, Orchard PJ, Bjoraker KJ, Ziegler RS, Shapiro EG, Charnas L. N-acetyl-L-cysteine improves outcome of advanced cerebral adrenoleukodystrophy. Bone Marrow Transplant. 2007;39(4):2115. PMid:17290278. http://dx.doi. org/10.1038/sj.bmt.1705571. 
12. Abt G, Vaghef $\mathrm{H}$, Gebhart $\mathrm{E}$, Dahlgren CV, Hellman B. The role of $\mathrm{N}$-acetylcysteine as a putative radioprotective agent on X-rayinduced DNA damage as evaluated by alkaline single-cell gel electrophoresis. Mutat Res. 1997;384(1):55-64. PMid:9201273. http://dx.doi. org/10.1016/S0921-8777(97)00013-X.

13. Browne RW, Armstrong D. Reduced glutathione and glutathione disulfide. Methods Mol Biol. 1998;108:347-52. PMid:9921543.

14. Aksenov MY, Markesbery WR. Changes in thiol content and expression of glutathione redox system genes in the hippocampus and cerebellum in Alzheimer's disease. Neurosci Lett. 2001;302(2-3):1415. PMid:11290407. http://dx.doi. org/10.1016/S0304-3940(01)01636-6.

15. Lowry OH, Rosebrough NJ, Farr AL, Randall RJ. Protein measurement with the Folin phenol reagent. J Biol Chem. 1951;193(1):265-75. PMid:14907713.

16. Deon M, Sitta A, Barschak AG, Coelho DM, Pigatto M, Schmitt $\mathrm{GO}$, et al. Induction of lipid peroxidation and decrease of antioxidant defenses in symptomatic and asymptomatic patients with X-linked adrenoleukodystrophy. Int
J Dev Neurosci. 2007;25(7):4414. PMid:17928186. http://dx.doi. org/10.1016/j.ijdevneu.2007.08.008.

17. Rockenbach FJ, Deon M, Marchese DP, Manfredini V, Mescka C, Ribas GS, et al. The effect of bone marrow transplantation on oxidative stress in X-linked adrenoleukodystrophy. Mol Genet Metab. 2012;106(2):2316. PMid:22525090. http://dx.doi. org/10.1016/j.ymgme.2012.03.019.

18. Halliwell B, Gutteridge JMC. Free radicals in biology and medicine. Oxford: Oxford University Press; 2007.

19. Johnson WM, Wilson-Delfosse AL, Mieyal JJ. Dysregulation of glutathione homeostasis in neurodegenerative diseases. Nutrients. 2012;4(10):1399440. PMid:23201762. http://dx.doi. org/10.3390/nu4101399.

20. Farr SA, Poon HF, Dogrukol-Ak D, Drake J, Banks WA, Eyerman E, et al. The antioxidants alpha-lipoic acid and $\mathrm{N}$-acetylcysteine reverse memory impairment and brain oxidative stress in aged SAMP8 mice. J Neurochem. 2003;84(5):1173-83. PMid:12603840. http://dx.doi.org/10.1046/j.14714159.2003.01580.x.

21. Tchantchou F, Graves M, Rogers E, Ortiz D, Shea TB. N-acetyl cysteine alleviates oxidative damage to central nervous system of ApoE-deficient mice following folate and vitamin E-deficiency. J Alzheimers Dis. 2005;7(2):135-8, discussion 173-80. PMid:15851851.

22. Terrill JR, Radley-Crabb HG, Grounds MD, Arthur PG. N-Acetylcysteine treatment of dystrophic mdx mice results in protein thiol modifications and inhibition of exercise induced myofibre necrosis. Neuromuscul Disord. 2012;22(5):427-34. PMid:22206641. http://dx.doi. org/10.1016/j.nmd.2011.11.007.

23. Holmay MJ, Terpstra M, Coles LD, Mishra U, Ahlskog M, Öz $\mathrm{G}$, et al. N-acetylcysteine boosts brain and blood glutathione in Gaucher and Parkinson diseases. Clin Neuropharmacol. 2013;36(4):103-6. PMid:23860343. http://dx.doi.org/10.1097/ WNF.0b013e31829ae713.

24. Rushworth GF, Megson IL. Existing and potential therapeutic uses for $\mathrm{N}$-acetylcysteine: the need for conversion to intracellular glutathione for antioxidant benefits. Pharmacol Ther. 2014;141(2):150-9. PMid:24080471. http://dx.doi.org/10.1016/j. pharmthera.2013.09.006.

Received: Dec 06, 2016 Accepted: Feb 13, 2017 